\title{
A fuzzy intelligent system for land consolidation - a case study in Shunde, China
}

\author{
J. Wang ${ }^{1,2,3,4}$, A. Ge $\mathbf{e}^{1,5}$, Y. Hu $\mathbf{H}^{1,2,3,4}$, C. $\mathbf{L i}^{2,3,6}$, and L. Wang ${ }^{1,2,3,4}$ \\ ${ }^{1}$ College of Mathematics and Informatics, South China Agricultural University, Guangzhou, Guangdong, China \\ ${ }^{2}$ Guangdong Province Key Laboratory of Land Use and Consolidation, Guangzhou, Guangdong, China \\ ${ }^{3}$ Key Laboratory of the Ministry of Land and Resources for Construction Land Transformation, Guangzhou, \\ Guangdong, China \\ ${ }^{4}$ Field Science Base of the Ministry of Land and Resources for South China Land Consolidation, Guangzhou, \\ Guangdong, China \\ ${ }^{5}$ Foshan City Shunde District Decision Consultation and Policy Research Office, Shunde District, Foshan City, \\ Guangdong, China \\ ${ }^{6}$ Guangdong Youyuan Land Information Technology Co., Ltd, Guangzhou, Guangdong, China
}

Correspondence to: J. Wang (wangphoenix@163.com)

Received: 16 March 2015 - Published in Solid Earth Discuss.: 16 April 2015

Revised: 3 August 2015 - Accepted: 4 August 2015 - Published: 20 August 2015

\begin{abstract}
Traditionally, potential evaluation methods for farmland consolidation have depended mainly on the experts' experiences, statistical computations or subjective adjustments. Some biases usually exist in the results. Thus, computer-aided technology has become essential. In this study, an intelligent evaluation system based on a fuzzy decision tree was established, and this system can deal with numerical data, discrete data and symbolic data. When the original land data are input, the level of potential of the agricultural land for development will be output by this new model. The provision of objective proof for decision-making by authorities in rural management is helpful. Agricultural land data characteristically comprise large volumes, complex varieties and more indexes. In land consolidation, it is very important to construct an effective index system. A group of indexes need to be selected for land consolidation. In this article, a fuzzy measure was adopted to accomplish the selection of specific features. A fuzzy integral based on a fuzzy measure is a type of fusion tool. The optimal solution with the fewest non-zero elements was obtained for the fuzzy measure by solving a fuzzy integral. This algorithm provides a quick and optimal way to identify the land-index system when preparing to conduct land consolidation. This new research was applied to Shunde's "Three Old" consolidation project which provides the data. Our estimation system was
\end{abstract}

compared with a conventional evaluation system that is still accepted by the public. Our results prove to be consistent, and the new model is more automatic and intelligent. The results of this estimation system are significant for informing decision-making in land consolidation.

\section{Introduction}

Rural conditions which include environmental, ecological, living and cultivated land conditions have been destroyed in many countries of the world, and these conditions may continue to worsen (Cerdà et al., 2007; König et al., 2014; Tilahun et al., 2013). Soil can provide plant-growing conditions and filter underground water (Keesstra et al., 2012). It is so important for human lives that we must take some measures to protect the soil. In China, soil erosion, conservation and the eco-environment are changing and the "Grainfor-Green" eco-restoration program in the Loess Plateau has been developed as an important project (Zhao et al., 2013, 2015). A large and fast growing population and rural land overuse has led to Karst rocky desertification (KRD) in southwest China (Yan and Cai, 2015). Land-cover changes affect the soil organic carbon (SOC) and soil total nitrogen (STN) in the Daqing prefecture (Yu et al., 2014). Convert- 
ing Pinus to eucalyptus plantations changed the soil quality in South China (Zhang et al., 2015). Climate change and human activity have had a major effect on dust storms in northern China (Wang et al., 2013). So, we need to find a good way to solve these situations. There are many methods to control soil erosion (Mekonnen et al., 2015). Land consolidation (LC) is an effective instrument in rural development. Land consolidation comprises two main components: land reallocation and agrarian spatial planning. Land reallocation can be referred to as land readjustment, which involves the rearrangement of ownership in terms of parcels (size, shape and location) and rights (land exchange). Land reallocation is the core part of the land-consolidation approach. Agrarian spatial planning includes the provision of the necessary infrastructure such as roads, irrigation systems, drainage systems, landscaping, environmental management, village renewal and soil conservation (Thomas, 2006a). LC aims to increase land-processing efficiency (Blaikie and Sadeque, 2000; Niroula and Thapa, 2007) and support rural development (Sklenicka, 2006). Thus, LC is very important for rural development. How to proceed with land consolidation and how to evaluate the potential of land for consolidation are crucial problems to be addressed by authorities. The "Three Old" project, which is underway in China, is a typical approach to exploring farmland potential. This "Three Old" reformation can help by returning the entire profit obtained from selling farmland to the farmer. But, all money must be used for reformation of old villages and the construction of new villages. Farmers are encouraged to live in a centralized manner in order to free up plenty of farmland to simultaneously achieve large-scale agriculture management and village construction. Land consolidation is the key to the "Three Old" project.

To date, many researchers have focused on the potential for evaluating world land use. The Turkish Statistical Institute (TUIK, 2001) performed a general agricultural census in Turkey. LC projects were developed depending totally on the experiences of those experts involved (Sonnenberg, 1996; Thomas, 2005, 2006b). A framework for the classification of peatland disturbance was proposed (Connolly and Holden, 2013). This model is still subjective. Some scholars have proposed statistical methods for classifying land. A quantitative change detection method was adopted for classifying land-cover conversions in the eastern Mediterranean coastal wetlands of Turkey (Alphan, 2012). Multivariate statistical approaches were used to determine the criteria of grassland degradation. Hierarchical classification highlighted two broad classes in the Sanjiangyuan region (Li et al., 2014). Intelligent systems can interpret the professional result and enhance the cognitive performance of decision makers. A fuzzy expert system was proposed for analysing and solving uncertainty in farmland data (Cay and Iscan, 2011; Oinam et al., 2014). Unsupervised classification of the agricultural area of South Australia was used for severity levels of salt-affected soil based on satellite imagery (Setia et al., 2013). A spa- tial decision support system (SDSS)-based land reallocation model was developed to reallocate newly created regular-size parcels to landowners in land-consolidation projects (Cay and Iscan, 2011). A combined set of digital soil mapping and sampling design techniques was used to quantify and predict the spatial distribution of soil properties in southern Arizona, USA (Holleran et al., 2015). The models are constructed using computer technology, which is faster and more trustworthy. Still, the results are not intuitive or natural. In this paper, a fuzzy decision tree system for LC is proposed. The characteristics of the decision tree include strong interpretability, high accuracy and rapid implementation, thereby surpassing traditional models.

In agricultural land consolidation, the land-index system is important for farmland evaluation. Therefore, the selection of land indexes affects evaluations and decisions. Currently, many researchers focus on the optimization and selection of a land-index system. Saaty (2010) proposed an index-selection method based on an analytic hierarchy process with weights (Saaty and Peniwati, 2008). He proposed the least squares method (LSM) and the logarithmic least squares method (LLSM) for confirming the previous weights (Saaty, 2010). However, land indexes are multiple and very complicated. These indexes may be related to society, economics and ecology. For example, a functional classification index (FCIi) for rangelands combines the productive value (GPi), ecological services value (GEi), ecological sensitivity (ESIi) and seasonal grazing importance (SGIi) (Liu et al., 2014). Traditionally, a land-index system was constructed according to the experiences of the experts. Due to human factors, however, these evaluations lost objectivity and consistency. Obtaining a set of accurate weights in the analytic hierarchy process is too difficult. The study of soils requires an interdisciplinary approach (Brevik et al., 2015).

In this article, a new method based on a computational tool - the fuzzy measure - is proposed for land-index selection. This method avoids human effects and confirms the final index system objectively. A fuzzy measure can describe the importance of the single index and the combination of indexes for decision-making (Sugeno, 1974). A fuzzy measure with sparse values can be obtained by using the L1-norm method (Hastie et al., 2001). Those indexes with non-zero fuzzy measures are kept in the final index system. Based on the new index system, a fuzzy decision tree model will be constructed to finish the evaluation of land level for consolidation.

The "Three Old" reconstruction project in the Shunde district of the Guangdong province in China was taken as the study case. The "Three Old" refers to old villages, old factories and old towns. The aim of the "Three Old" reformation is to encourage peasants to live in centralized residences and empty large blocks of cultivated land for the development of large-scale agriculture. Therefore, the "Three Old" project is mainly focused on the reconstruction of old villages. Our model is proposed for evaluating the development potential of these reconstructed villages and to provide sup- 


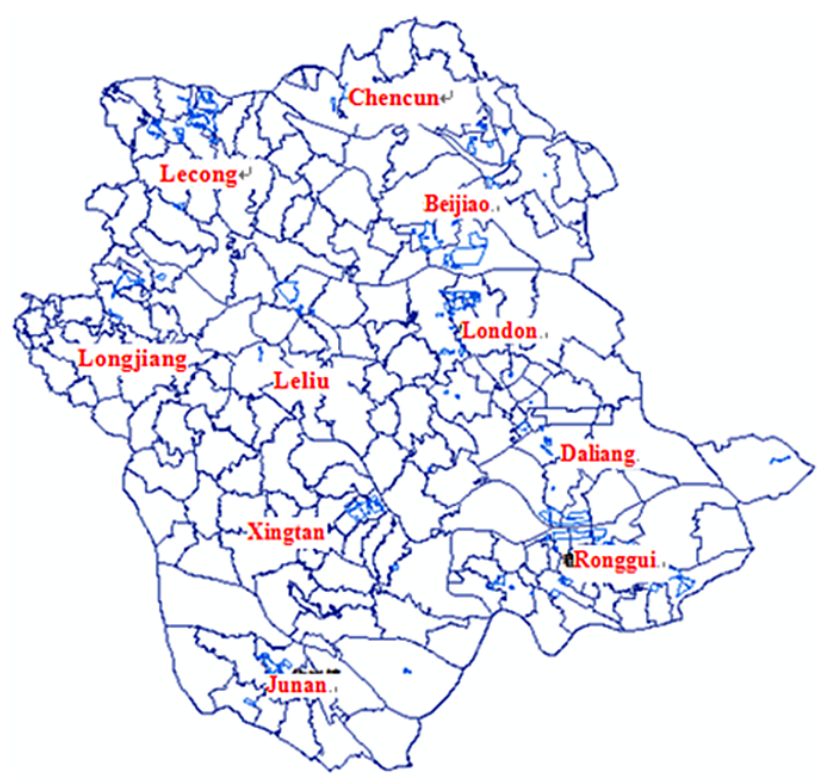

Figure 1. The administrative division of the "Three Old" project of Shunde.

port for decision-making in agricultural development. The whole article is arranged as follows. The introduction has been given in Sect. 1. Section 2 shows the background and the data drawn from Shunde's "Three Old" project. The next section presents the preliminaries, definitions and the new system. The results and analysis are shown in Sect. 4. Summaries and policy advice are provided in Sect. 5 .

\section{Materials and data description}

Shunde is the pioneer in economic reformation in Guangdong. Its development from an agricultural city to an industrial district has spanned 10 years. Shunde is located in southern Guangdong and in the middle of the ZhuJiang River Triangle plain, which extends east to Panyu; north to Foshan; and is contiguous with Shenzhen, Hongkong and Macau. The special geographical location, as shown in Fig. 1, dictates the degree of reformation. In this rapidly developing economy, a large amount of cultivated land resources have been destroyed. This extensive pattern of land use is difficult to sustain. The contradiction between supply and demand of cultivated land resources is increasingly becoming acute. These factors restrict rural sustainable development. Thus, the government proposed the "Three Old" consolidation project to strengthen the management of land with construction and to encourage saving land for use in intensive agriculture. The evaluation model can be popularized to these areas, each of which is faced with the same problems, such as destroyed land and the contradiction between supply and demand.
Table 1. Statistical data about the types and area of "Three Old" reconstruction.

\begin{tabular}{lrrrr}
\hline State & Old factories & Old towns & Old villages & In total \\
\hline Finished & 4437.91 & 568.27 & 44.68 & 5050.86 \\
Ongoing & 4196.71 & 354.35 & 563.51 & 5114.57 \\
Not started & 49634.37 & 9074.25 & 8425.73 & 67134.35 \\
\hline In total & 58268.99 & 9996.86 & 9033.92 & 77299.77 \\
\hline
\end{tabular}

Table 2. The proportion of land according to construction type.

\begin{tabular}{lrrr}
\hline Construction type & Old towns & Old villages & Old factories \\
\hline Proportion of land $(\%)$ & 2.16 & 1.95 & 12.61 \\
\hline
\end{tabular}

Table 3. The percentages of each state of reconstruction.

\begin{tabular}{lrrr}
\hline States & Finished & Not started & Ongoing \\
\hline Percentage $(\%)$ & 6.53 & 86.85 & 6.62 \\
\hline
\end{tabular}

\subsection{Pre-process data}

The potential evaluation of "Three Old" land consolidation is mainly focused on those land blocks that contain plots and buildings. There are a total of 477 sub-projects, of which 23 sub-projects with 5050.86 acres have been completed, 22 are currently being reconstructed and 432 with 67134.35 acres have not been started, as shown in Table 1. This project is characterized by large areas of land and a large quantity, a wide range and a concentrated distribution of sub-projects. The total area reaches 77299.77 acres, which is $16.73 \%$ of the land with construction in cities and towns. The ratios of each type of the "Three Old" lands are shown in Tables 2 and 3.

In this project, the evaluation targets are characterized by multiple features. It is necessary to normalize all feature values to cancel the influence of these variables and values. One general method is $0-1$ normalization, which scales the feature by bringing all values into the range $[0,1]$. It is also called unity-based normalization.

Let $X_{\max _{i j}}$ indicate the maximum value and $X_{\min _{i j}}$ indicate the minimum value for the $j$ th feature of the $i$ th case. The normalization for each variable can be computed according to the following equations.

For the active index:

$S_{i j}=\frac{X_{i j}-\min X_{i j}}{\max X_{i j}-\min X_{i j}}$

for the negative index:

$S_{i j}=\frac{\max X_{i j}-X_{i j}}{\max X_{i j}-\min X_{i j}}$. 
Table 4. The results from the rough set selection and the fuzzy measure selection.

\begin{tabular}{|c|c|c|}
\hline Criteria layer & Subcriteria layer & Evaluation indexes \\
\hline \multirow[t]{3}{*}{ Land use (A) } & Landscapes & $\begin{array}{l}\text { Building coordination } \\
\text { Block crush degree }\end{array}$ \\
\hline & Building situation & $\begin{array}{l}\text { Building age } \\
\text { Building structure }\end{array}$ \\
\hline & Development strength & $\begin{array}{l}\text { Volume ratio } \\
\text { changing of building density }\end{array}$ \\
\hline Economical factors (B) & $\begin{array}{l}\text { Basic land price } \\
\text { Investment strength } \\
\text { Net income per capita } \\
\text { Population density }\end{array}$ & $\begin{array}{l}\text { Basic land price } \\
\text { Changing degree of investment amount } \\
\text { Net income per capita } \\
\text { Population density }\end{array}$ \\
\hline \multirow[t]{3}{*}{ Social factors $(\mathrm{C})$} & Social welfare & $\begin{array}{l}\text { Medical and sanity } \\
\text { Education } \\
\text { Public welfare (park, square) }\end{array}$ \\
\hline & Basic facilities & Traffic connectivity \\
\hline & Green degree & Green ratio \\
\hline Ecological factors (D) & Ecological environment & $\begin{array}{l}\text { Noisy pollution } \\
\text { Air pollution } \\
\text { Water pollution }\end{array}$ \\
\hline \multirow[t]{3}{*}{ Policy (E) } & Compensation and emplacement & $\begin{array}{l}\text { Compensation } \\
\text { Emplacement }\end{array}$ \\
\hline & Responding & Responding activity \\
\hline & Management & Public participation \\
\hline
\end{tabular}

According to the previous formula, the range of $X^{\prime}$ is between 0 and 1 . The distribution of each $X^{\prime}$ is the same as that of the original value of $X$. The advantage of $0-1$ normalization is that the best situation is always 1 and the worst one is always 0 , depending on if the value is negative or active. However, this process disregards the differences among the features' values, which means the relationship among features cannot be determined. However, the $0-1$ normalization is still the simplest method.

\subsection{Land-index system}

In this study, we began the investigation by collecting materials about land indexes, land levels, the construction being finished or not and so on, using spatial image recognition, conducting field investigations and assessing results of a questionnaire for the land potential evaluation. All factors, including the land-use state, and economic, social, ecological, environmental and policy factors have been considered. The results will be summarized and analysed so that the entire contribution of the "Three Old" project can be precisely acknowledged. All indexes being considered are described in Table 4.
A new model was applied to the Shunde data to determine the index system, which is important for the study. Several classical evaluation models were adopted for testing the feature selection results. However, the current number of indexes of the "Three Old" data is too large for computing the fuzzy integral. It takes a very long time to acquire the fuzzy measure. Therefore, feature selection is a necessary step. Based on previous research, reduction in rough sets (Pawlak, 1982, 1991) is the most effective way to process the data before selecting the indexes and evaluating potential.

\section{Evaluation method and model}

In land consolidation, we must deal with data collected by humans from many locations. These data may be uncertain and noisy. It is necessary to adopt an objective tool to solve the problem of subjectivity. Thus, a fuzzy decision tree was chosen for use in this study. Fuzzy logic was proposed by Zadeh (1965), and this technique can describe and handle vague and ambiguous data. Fuzzy logic is a form of many-valued logic; it deals with reasoning that is approximate rather than fixed and exact. Compared to traditional binary sets (where variables may take on true or false values) 
fuzzy logic variables may have a true value that ranges in degree from 0 to 1 . Fuzzy logic has been extended to handle the concept of partial truth, where the true value may range between completely true and completely false. Furthermore, when linguistic variables are used, these degrees may be managed by specific functions. Irrationality can be described in terms of what is known as the "fuzzjective". Fuzzy logic has been applied to many fields, from control theory to artificial intelligence.

\subsection{Fuzzy set theory}

Fuzzy set theory is primarily concerned with quantifying and reasoning by using natural language in which words can have ambiguous meanings. This can be thought of as an extension of traditional crisp sets, in which each element must either be in or not in a set. Fuzzy sets are defined on a non-fuzzy universe of discourse, which is an ordinary set (Wang and Lee, 2006). A fuzzy set is characterized by a membership function $\mu_{F}(x)$, which assigns a membership degree $\mu_{F}(x) \in[0,1]$ to every element. When $\mu_{A}(x)>0$, an element $x \in U$ will be in a fuzzy set $F$. That is, $\mu_{F}(x)=1$ represents a full member (Zimmermann, 1991). Membership functions can either be chosen based on the user's experience or by using optimization procedures (Jang, 1992; Horikowa et al, 1992). Typically, a fuzzy subset $A$ can be represented as

$A=\left\{\frac{\mu_{A}\left(x_{1}\right)}{x_{1}}, \frac{\mu_{A}\left(x_{2}\right)}{x_{2}}, \ldots, \frac{\mu_{A}\left(x_{n}\right)}{x_{n}}\right\}$.

Fuzzification is the process of changing a real scalar value into a fuzzy value (Tsoukalas and Uhrig, 1993). This is achieved with the different types of fuzzifiers. In this paper, the trapezoidal or triangular fuzzifier is adopted. Fuzzification of a real-valued variable is performed with intuition, experience and analysis of the set of rules and conditions associated with the input data variables. There is no fixed set of procedures for fuzzification.

\subsection{Fuzzy decision tree construction}

Fuzzy sets and fuzzy logic are able to deal with languagerelated uncertainties by fuzzifying, while providing a symbolic framework for increasing knowledge comprehensibility. Fuzzy decision trees (FDT) differ from traditional crisp decision trees in three respects (Janikow, 1998): the splitting of criteria based on fuzzy restrictions, the different inferring procedures and defining the fuzzy sets that represent the data. The heuristic for FDT is based on minimal ambiguity.

The procedure for constructing FDT is mainly as follows:

1. place all data into one node as the root;

2. select one feature with low entropy to divide the cases in the root into different son nodes according to the different feature values;
3. for each son node, repeat the same action until the node cannot be divided, i.e. leaf.

Given that non-leaf node $S$ has $n$ fuzzy features $A^{(1)}, A^{(2)}, \ldots, A^{(n)}$ to be selected, for every $k(1 \leq k \leq$ $n$ ), fuzzy feature $A^{(k)}$ takes $m_{k}$ linguistic values as $T_{1}^{(k)}, T_{2}^{(k)}, \ldots, T_{m_{k}}^{(k)} . A^{(n+1)}$ represents a class that takes values as $T_{1}^{(n+1)}, T_{2}^{(n+1)}, \ldots, T_{m}^{(n+1)}$. In symbolic data sets, the value of features and classes are 0 or 1 . For a better description, $\|S\|$ is defined as representing the number of examples of the non-leaf node $S$.

The tree grows based on the following computing results. For each value of feature, $T_{i}^{(k)}(1 \leq k \leq n, 1 \leq i \leq$ $m_{k}$ ), the relative frequency about the $j$ th class $T_{i}^{(n+1)}$ on non-leaf node $S$ is defined as $p_{i j}^{(k)}=\left|S_{i} \cap S_{j}\right| /\left|S_{i}\right|$, in which $S_{i}$ is the subset of $S$ for which feature $A^{(k)}$ has value $T_{i}^{(k)}$ (i.e. $S_{i}=\left\{s \in S \mid A^{(k)}=T_{i}^{(k)}\right\}$ ) and $S_{j}$ is the subset of $S$ too, for which $A^{(n+1)}$ takes value $T_{j}^{(n+1)}$ (i.e. $S_{j}=\left\{s \in S \mid A^{(n+1)}=T_{j}^{(n+1)}\right\}$ ). On non-leaf node $S$, the classification entropy of $T_{i}^{(k)}$ is defined as $\operatorname{Entr}_{i}^{(k)}=$ $-\sum_{j=1}^{m}\left|S_{i} \cap S_{j}\right| /\left|S_{i}\right| \cdot \log _{2}\left|S_{i} \cap S_{j}\right| /\left|S_{i}\right|$.

The average classification entropy of the $k$ th feature is defined as $E_{k}=\sum_{i=1}^{m_{k}} \omega_{i} \operatorname{Entr}_{i}^{(k)}$, in which $\omega_{i}$ represents the weight of the $i$ th value $T_{i}^{(k)}, \omega_{i}=\left|S_{i}\right| /|S|$. Thus, we can summarize to get the entropy, i.e. $E_{k}=\sum_{i=1}^{m_{k}} \frac{\left|S_{i}\right|}{|S|} \operatorname{Entr}_{i}^{(k)}$.

FDT aim to find out one feature that can make the average classification entropy the minimum, i.e. selecting one integer $k_{0}$, so that $E_{k_{0}}=\min _{1 \leq k \leq n} E_{k}$.

\subsection{Land-index selection}

A data set consisting of $L$ examples, called a training set, are given, where each record contains the value of a decisive feature, $Y$, and the value of predictive features $x_{1}, x_{2}, \ldots, x_{n}$. The positive integer $L$ is the data size. The decisive feature indicates the class to which each example belongs, and it is a categorical feature with values coming from an unordered finite domain. The set of all possible values of the decisive feature is denoted by $Y=y_{1}, y_{2}, \ldots, y_{m}$, where each $y_{k}, k=1,2, \ldots, m$, refers to a specified class. The predictive features are numerical, and their values are described by an $n$-dimensional vector, $\left(f\left(x_{1}\right), f\left(x_{2}\right), \ldots, f\left(x_{n}\right)\right)$. The range of the vector, a subset of $n$-dimensional Euclidean space, is called the feature space. The $j$ th observation consists of $n$ predictive features and the decisive feature can be denoted by $\left(f_{j}\left(x_{1}\right), f_{j}\left(x_{2}\right), \ldots, f_{j}\left(x_{n}\right), Y_{j}\right), j=1,2, \ldots, L$. Before introducing the model, we state the fundamental concepts according to the following requirements.

\subsection{Fuzzy measure}

Let $X=x_{1}, x_{2}, \ldots, x_{n}$ be a non-empty finite set of features and $P(X)$ be the power set of $X$. To further understand the 
practical meaning of the fuzzy measure, the elements in a universal set $X$ are considered as a set of predictive features. Then, each value of the fuzzy measure is assigned to describe the influence of each predictive feature or combination of them to the objective. The influences of the predictive features to the objective are dependent due to the non-additivity of the fuzzy measure. If $\mu(X)=1$, then $\mu$ is said to be regular. The monotonicity and non-negativity of the fuzzy measure are too restrictive to apply for more problems. Thus, the signed fuzzy measure, which is a generalization of the fuzzy measure, has been defined (Murofushi et al., 1994; Grabisch et al., 2000) and adopted.

A signed fuzzy measure can set its value as being negative and free the monotonicity constraint. Thus, it is more flexible to describe the contribution of the individual and combination of the predictive features for some targets. Let $f$ be a real-valued function on $X$. The fuzzy integral of $f$ with respect to $\mu$ is obtained by

$\int f \mathrm{~d} \mu=\int_{-\infty}^{0}\left[\mu\left(F_{\alpha}\right)-\mu(X)\right] \mathrm{d} \alpha+\int_{0}^{\infty} \mu\left(F_{\alpha}\right) \mathrm{d} \alpha$,

where $F_{\alpha}=\{x \mid f(x) \geq \alpha\}$, for any $\alpha \in(-\infty, \infty)$, is called the $\alpha$-cut of $f$.

Usually, for calculating the value of the fuzzy integral for the given real-valued function $f$, the values of $f$, i.e. $f\left(x_{1}\right), f\left(x_{2}\right), \ldots, f\left(x_{n}\right)$, can be sorted in a nondecreasing order so that $f\left(x_{1}^{\prime}\right) \leq f\left(x_{2}^{\prime}\right) \leq \ldots \leq f\left(x_{n}^{\prime}\right)$, where $\left(x_{1}^{\prime}, x_{2}^{\prime}, \ldots x_{n}^{\prime}\right)$ is a certain permutation of $\left(x_{1}, x_{2}, \ldots, x_{n}\right)$. Thus, the value of the fuzzy integral can be computed by

$$
\begin{aligned}
\int f \mathrm{~d} \mu= & \sum_{i=1}^{n}\left[f\left(x_{i}^{\prime}\right)-f\left(x_{i-1}^{\prime}\right)\right] \mu\left(\left\{x_{i}^{\prime}, x_{i+1}^{\prime}, \ldots x_{n}^{\prime}\right\}\right), \\
& \text { where } f\left(x_{0}^{\prime}\right)=0
\end{aligned}
$$

The fuzzy integral can deal with non-linear space based on linear operators.

\subsection{Transformation of the fuzzy integral}

To be convenient, Wang (2003) proposed a new scheme to calculate the value of a fuzzy integral by the inner product of two $\left(2^{n}-1\right)$-dimension vectors as

$$
\int f \mathrm{~d} \mu=\sum_{j=1}^{2^{n}-1} z_{j} \mu_{j}
$$

where

$$
\begin{aligned}
& z_{j}=
\end{aligned}
$$

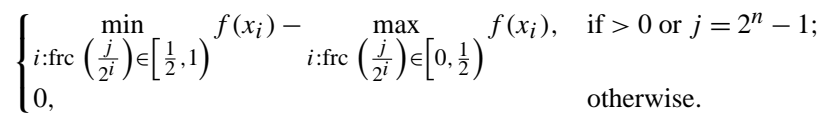

for $j=1,2, \ldots, 2^{n}-1$ with a convention, in which the maximum on the empty set is zero. Here, $\operatorname{frc}\left(\frac{j}{2^{i}}\right)$ denotes the fractional part of $\frac{j}{2^{i}}$. In Eq. (4), if $j$ is expressed in the binary form $j_{n} j_{n-1} \ldots j_{1}$, then $\left\{i \mid \operatorname{frc}\left(\frac{j}{2^{i}}\right) \in\left[\frac{1}{2}, 1\right)\right\}=\left\{i \mid j_{i}=1\right\}$ and $\left\{i \mid \operatorname{frc}\left(\frac{j}{2^{i}}\right) \in\left[0, \frac{1}{2}\right)\right\}=\left\{i \mid j_{i}=0\right\}$.

A significant advantage of this new computation scheme is that it can easily discover the coefficient matrix of a system of linear equations with the unknown variable $\mu$. The fuzzy integral can be applied to further applications, such as regression and classification (Wang, 2003; Wang et al., 1998; Leung et al., 2002). In those practical applications, values of the signed fuzzy measure are to be estimated using the training data sets as unknown parameters. The new scheme makes it more convenient by using an algebraic method, such as the least squares method, to estimate the value of $\mu$ and reduce the complexity of computation.

After adopting the transformation, the fuzzy measure for a known data set can be obtained by using L1-norm regularization.

\subsection{Solution of fuzzy measure}

For determining the fuzzy measure, researchers have proposed many methods. In our past work, the genetic algorithm (GA) was used to learn the value of the fuzzy measure. In this article, a new method was adopted based on L1-norm regularization.

For solving regression problems, the least squares estimation is the most popular function, alternatively referred to as the minimum of the residual sum of squared errors (RSS) (Hastie et al., 2001): RSS $=\sum_{i=1}^{n}\left(y_{i}-\omega_{0}-\sum_{j=1}^{p} x_{i j} \omega_{i}\right)^{2}$. Regularization addresses the numerical instability of the matrix inversion and produces lower variance models. It is obvious that this minimizes the following penalized RSS function with respect to $\omega$ and $\omega_{0}: \sum_{i=1}^{n}\left(y_{i}-\omega_{0}-\sum_{j=1}^{p} x_{i j} \omega_{i}\right)^{2}+\lambda \sum_{j=1}^{p} \omega_{j}^{2}$. This belongs to L2 regularization. For simplifying the notation, it can be transferred to the following form (in matrix notation): $\|X \omega-y\|_{2}^{2}+\lambda\|\omega\|_{2}^{2}$. Although L2 regularization is an effective means of achieving numerical stability and increasing predictive performance, it cannot address another important problem with least squares estimation, i.e. parsimony of the model and interpretability of the coefficient values. It does not encourage sparsity in some cases (Tibshirani, 1996). Thus, L1-norm has been a trend to replace the L2norm. The L1 regularization has many of the same beneficial properties as L2 regularization; meanwhile, it can obtain a sparse solution, which is more easily interpreted (Hastie et al., 2001) and it is what our model needs. With a fuzzy integral, determining the fuzzy measure is the key point. The fuzzy measure represents the importance of features and the interaction degree of the combined features.

We hope to get a solution of the fuzzy measure with the fewest non-zero values corresponding to the most important features and feature combinations. Using L1-norm regularization, the following formula can be minimized to 
Table 5. The results from rough set selection and fuzzy measure selection.

\begin{tabular}{llll}
\hline & \multicolumn{3}{c}{ Types } \\
\cline { 2 - 4 } Performance & All features & With RS selection & With FM selection \\
& & & \\
\hline Prediction accuracy & $89.12 \%$ & $93.06 \%$ & $94.34 \%$ \\
Selected features & all & $\{4,6,8,9,10,11,15\}$ & $\{4,6,8,9,10\}$ \\
Number of leaves & 10 & 7 & 4 \\
Size of tree & 19 & 13 & 7 \\
\hline
\end{tabular}

Note, selected features denote: all indexes, indexes selected by the rough set and indexes selected by the fuzzy measure. Prediction accuracy is the accuracy using different index groups. The number of leaves shows the leaves of the decision tree and the size of tree shows the number of all nodes in the decision tree.

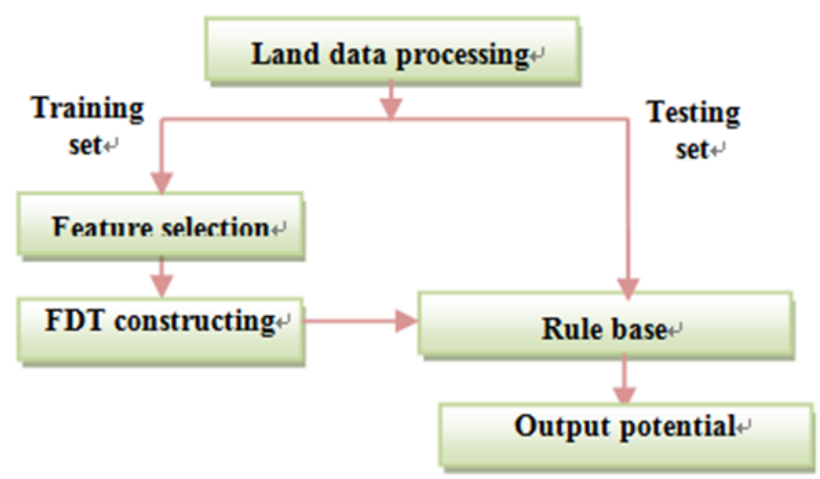

Figure 2. Flowchart of the model construction.

reduce the number of non-zeroes in the fuzzy measure: $\left\|\sum_{j=1}^{2^{n}-1} z_{j} \mu_{j}-y\right\|_{2}^{2}+\lambda\|\mu\|_{1}$. The compression degree for the fuzzy measure can be controlled by adjusting the parameter $\lambda$. Shevade and Keerthi (2003) proposed the least absolute selection and shrinkage operator (LASSO) model, which is based on the Gauss-Seidel method. The obvious advantages of the Gauss-Seidel approach are simplicity and low iteration cost. This type of LASSO was adopted to solve the L1-norm problem. Finally, the optimal fuzzy measure can be obtained and the corresponding land-index system is constructed. For example, the fuzzy measure is solved as $\{0,0.6,0,0,0,0.4,0\}$ for three indexes $\left\{x_{1}, x_{2}, x_{3}\right\}$. Then, indexes or index combinations corresponding to non-zero are $\left\{x_{2}\right\}$ and $\left\{x_{2}, x_{3}\right\}$, which will be important for the final decision.

\section{Experiments and analysis}

Before building the evaluation model, we need the feature selection to reduce the complexity of computation by deleting the redundant information. WEKA exploit platform was adopted to call the feature selection function and develop the evaluation model. After completing the feature selection, the FDT is constructed on the pre-processed data for evaluat- ing the comprehensive potential. The data from the Shunde project contain 477 blocks, 27 of which have completed reformation and can be used as the training set.

The model construction can be presented as shown in Fig. 2.

After applying the L1-norm method to determine the fuzzy measure, the parameter $\lambda$ in the L1-norm method is used for controlling the degree of compression for reducing the nonzeroes. The value of $\lambda$ was set as $0,1,5,10,20,50$ and 100 . The larger the value of $\lambda$ is, the fewer the number of zeroes in the solution. The compressed fuzzy measure can simplify the computation of the fuzzy integral at the cost of performance. It needs to select an appropriate value for $\lambda$ to balance the complexity and the performance. Finally, the value of $\lambda$ is determined as 100. The binary forms corresponding to the fuzzy measure with values are $\{10000000\}$ and $\left\{\begin{array}{llll}1 & 111 & 100\end{array}\right.$ after being compressed by the L1-norm, which means keeping indexes from $x_{1}$ to $x_{5}$. All results with different feature selection methods are listed in Table 5. The final land-index system in the new model includes public welfare, net income per capita, air pollution, population density and water pollution. We can see that the size of the tree is compressed as the number of features is decreased and the performance is improved.

Based on those selected indexes, an evaluation model will be constructed. In this project, those blocks that have been finished and those that are ongoing with transformation present their actual potential and are used as a training set. The remainder, which contains those that have not yet been started, are tested via comparison with the conclusions that have been drawn from these statistics and this analysis. All artificial marks are removed from the original data. The final data set contains 27 predictive features and three levels of potential. Level 1 means the highest potential, level 2 represents the medium type, and level 3 is the worst grade for transformation. All results are listed in Table 6 to show the situation of the predicted potential of each town.

Assuming that the potential marked by experience is the destination classification, the prediction results of the fuzzy decision tree, which is $89.12 \%$, shows high consistency 
Table 6. The potential level of each town.

\begin{tabular}{llllll}
\hline District & $\begin{array}{l}\text { Number of } \\
\text { blocks }\end{array}$ & Level 1 & Level 2 & Level 3 & $\begin{array}{l}\text { Ratio of } \\
\text { Level 2 }\end{array}$ \\
\hline Daliang & 55 & 0 & 8 & 47 & 14.55 \\
London & 55 & 0 & 7 & 48 & 12.73 \\
Ronggui & 59 & 0 & 13 & 46 & 22 \\
Leliu & 44 & 0 & 7 & 37 & 15.9 \\
Lecong & 62 & 0 & 14 & 48 & 22.58 \\
Junan & 11 & 0 & 2 & 9 & 18.18 \\
Longjiang & 99 & 0 & 27 & 72 & 27.27 \\
Beijiao & 25 & 0 & 3 & 22 & 12 \\
Chencun & 15 & 0 & 3 & 12 & 20 \\
Xingtan & 26 & 0 & 2 & 24 & 7.69 \\
\hline
\end{tabular}

with the artificial remarks and the actual land situation of Shunde's "Three Old" project. There is no block with level 1. It illustrates that there are no very old and battered buildings in the Shunde district. In all blocks, levels 2 and 3 exist. Those blocks in the second ranking are characteristic of an effective land-use rate and modest volume rate. However, due to the bad living environment and the ordinary location, the price will not increase greatly. The third level blocks present reasonable volume rate, buildings' density and good environmental quality. Some basic facilities need to be improved, so the transformation potential is not so high. Longjiang, Lecong and Ronggui are arranged as the top three towns according to the ratio of level 2, which are key targets that need to be transformed.

\section{Discussion}

For land reformation, the quality of land block needs to be pre-evaluated, as so far, there are many methods to test rural land. Most are based on subjective means such as the quantitative change detection method, multivariate statistical approach and hierarchical classification (Thomas, 2005, 2006b; Connolly and Holden, 2013). This kind of assessment is always biased for some experts. As information technology was developing, computer-aided methods were adopted to help evaluate objectively. The fuzzy system was first proposed to deal with the uncertainty of rural land (Cay and Iscan, 2011) and satellite data were used for analysing the level of agricultural land with a paddock-by-paddock approach (Setia et al., 2013). All these methods hoped to allow more informed decisions about sustainable agricultural management. A more intuitive intelligent system is urgently needed. The fuzzy decision tree method provides a kind of good understandability, a simple computation and a fast decision, which satisfies the requirement of land-level assessment.

Meanwhile the intelligent model based on FDT depends on the land-index system. The land indexes contain economic, social and environmental factors. Not all indexes are helpful for the final evaluation of land level, especially the "Three Old" project which is very complex and variant. We need to eliminate those negative and noisy values to reduce the land feature set. Traditionally, land-index selection has been based on experts' skill. A fuzzy measure was introduced to shift important land indexes. In the Shunde district, public welfare, net income per capita, air pollution, population density and water pollution were arranged in descending order of importance and used as the final set. Maybe the indexes will change with the reforming of land consolidation in the future. So the "Three Old" project needs to provide the data for selecting indexes and evaluating dynamically. Based on a new index system, our new model can produce a group of land levels according to potential. Decision makers can carry out the relative consolidation measure according to the results. For example, Longjiang is the most promising district in Shunde. The government can give the biggest support for reforming and constructing.

\section{Conclusions}

To date, the "Three Old" transformation project is just beginning to be developed in Guangdong, China. Study on the "Three Old" project is very useful for the land-consolidation field. However, research related to the potential of transformation is sparse. In this article, a soft computing method fuzzy decision tree - has been induced to evaluate the potential of blocks for transformation. Meanwhile, there are too many indexes for each land project. Some provide noisy information, which is not good for model construction and a final assessment. Thus, index screening is an essential part of land consolidation. The L1-norm method was used to solve the fuzzy measure with the fewest non-zeroes for selecting land indexes. After selecting the indexes, a fuzzy intelligent system was built based on a fuzzy decision tree for land potential evaluation; this system can be used to divide the consolidated blocks into different levels. The results are more scientific, explicable and intelligent. The assessment of potential as presented by FDT has reinforced the conclusions drawn by traditional methods. This study can provide supplementary support for decision-making.

Acknowledgements. This research is supported by the National Natural Science Foundation of China (no. 61202295) and the Ministry of Key Projects in the National Science \& Technology Pillar Program during the Twelfth Five-year Plan Period (no. 2013BAJ13B05).

Edited by: A. Cerdà 


\section{References}

Alphan, H.: Classifying land cover conversions in coastal wetlands in the Mediterranean: pairwise comparisons of Landsat images, Land Degrad. Dev., 23, 278-292, 2012.

Blaikie, P. M. and Sadeque, A. Z.: Policy in the High Himalayas: Environment and Development in the Himalayan Region, ICIMOD, Kathmandu, 2000.

Brevik, E. C., Cerdà, A., Mataix-Solera, J., Pereg, L., Quinton, J. N., Six, J., and Van Oost, K.: The interdisciplinary nature of SOIL, SOIL, 1, 117-129, doi:10.5194/soil-1-117-2015, 2015.

Cay, T. and Iscan, F.: Fuzzy expert system for land reallocation in land consolidation, Expert Syst. Appl., 38, 11055-11071, 2011.

Cerdà, A., Imeson, A. C., and Poesen, J.: Soil Water Erosion in Rural Areas, Special Issue, Catena, 71, 191-252, http://www. sciencedirect.com/science/journal/03418162/71/2, 2007.

Connolly, J. and Holden, N. M.: Classification of peatland disturbance, Land Degrad. Dev., 24, 548-555, 2013.

Grabisch, M., Murofushi, T., and Sugeno, M. (Eds.): Fuzzy Measures and Integrals: Theory and Applications, Physica-Verlag, Inc. Secaucus, NJ, USA, 2000.

Hastie, T., Tibshirani, R., and Friedman, J. H.: The Elements of Statistical Learning, Springer, New York, USA, 43-137, 2001.

Holleran, M., Levi, M., and Rasmussen, C.: Quantifying soil and critical zone variability in a forested catchment through digital soil mapping, SOIL, 1, 47-64, doi:10.5194/soil-1-47-2015, 2015.

Horikowa, S., Furahashi, T., and Uchikawa, Y.: On fuzzy modeling using fuzzy neural networks with back-propagation algorithm, IEEE T. Neural Networ., 3, 801-806, 1992.

Jang, J. S. R.: Self-learning fuzzy controllers based on temporal back-propagation, IEEE T. Neural Networ., 3, 714-723, 1992.

Janikow, C. Z.: Fuzzy decision trees: issues and methods, IEEE Trans. on Systems, Man, and Cybernetics-Part B, 28, 1-14, 1998.

Keesstra, S. D., Geissen, V., van Schaik, L., Mosse, K., and Piiranen, S.: Soil as a filter for groundwater quality, Curr. Opin. Environ. Sustain., 4, 507-516, doi:10.1016/j.cosust.2012.10.007, 2012.

König, H. J., Zhen, L., Helming, K., Uthes, S., Yang, L., Cao, X., and Wiggering, H.: Assessing the impact of the sloping land conversion programme on rural sustainability in Guyuan, Western China, Land Degrad. Dev., 25, 385-396, 2014.

Leung, K. S., Wong, M. L., Lam, W., Wang, Z., and Xu, K.: Learning nonlinear multiregression networks based on evolutionary computation, IEEE Trans. on Systems, Man and Cybernetics, Part B, 32, 630-644, 2002.

Li, X. L., Perry, G. L. W., Brierley, G., Sun, H. Q., Li, C. H., and Lu, G. X.: Quantitative assessment of degradation classifications for degraded alpine meadows (heitutan), Sanjiangyuan, western China, Land Degrad. Dev., 25, 417-427, 2014.

Liu, X. Y., Liang, T. G., Guo, Z. G., and Long, R. J.: A rangeland management pattern based on functional classification in the northern Tibetan region of China, Land Degrad. Dev., 25, 193 201, 2014

Mekonnen, M., Keesstra, S. D., Stroosnijder, L., Baartman, J. E. M., and Maroulis, J.: Soil conservation through sediment trapping: a review, Land Degrad. Dev., doi:10.1002/ldr.2308, onlin first, 2015

Mekonnen, M., Keesstra, S. D., Baartman, J. E., Ritsema, C. J., and Melesse, A. M.: Evaluating sediment storage dams: structural off-site sediment trapping measures in northwest Ethiopia, Cuad. Investigación Geográfica, 41, 7-22, doi:10.18172/cig.2643, 2015.

Murofushi, T., Sugeno, M., and Machida, M.: Non monotonic fuzzy measures and the Choquet integral, Fuzzy Set. Syst., 64, 73-86, 1994.

Niroula, G. S. and Thapa, G. B.: Impact of land fragmentation on input use, crop yield and production efficiency in the mountains of Nepal, Land Degrad. Dev., 18, 237-248, 2007.

Oinam, B. C., Marx, W., Scholten, T., and Wieprecht, S.: A Fuzzy Rule Base Approach for Developing A Soil Protection Index Map: A Case Study in The Upper Awash Basin, Ethiopian Highlands, Land Degrad. Dev., 25, 483-500, 2014.

Pawlak, Z.: Rough sets, Int. J. Parallel Prog., 11, 341-356, 1982.

Pawlak, Z.: Rough Sets: Theoretical Aspects of Reasoning about Data, Kluwer Academic Publishing, Dordrecht, the Netherlands, 1991.

Saaty, T. L.: Mathematical Principles of Decision Making, RWS Publications, Pittsburgh, Pennsylvania, USA, 2010.

Saaty, T. L. and Peniwati, K.: Group Decision Making: Drawing out and Reconciling Differences, RWS Publications, Pittsburgh, Pennsylvania, USA, 2008.

Setia, R., Lewis, M., Marschner, P., Raja Segaran, R., Summers, D., and Chittleborough, D.: Severity of salinity accurately detected and classified on a paddock scale with high resolution multispectral satellite imagery, Land Degrad. Dev., 24, 375-384, 2013.

Shevade, S. K. and Keerthi, S. S.: A simple and efficient algorithm for gene selection using sparse logistic regression, Bioinformatics, 19, 2246-2253, 2003.

Sklenicka, P.: Applying evaluation criteria for the land consolidation effect to three contrasting study areas in the Czech Republic, Land Use Policy, 23, 502-510, 2006.

Sonnenberg, J.: The European Dimensions and Land ManagementPolicy Issues (Land Readjustment and Land Consolidation as Tools for Development), FIG Commission 7, Hungary, 1996.

Sugeno, M.: Theory of Fuzzy Integrals and Its Applications, Doctoral thesis, Tokyo Institute of Technology, Tokyo, Japan, 1974.

Thomas, J.: Actual trends concerning land management, land readjustment and land consolidation in Europe, in: Report at the 7th Workshop and 8th MC Meeting of the Action G9 of COST, Greece, 9-11 June, 2005.

Thomas, J.: Property rights, land fragmentation and the emerging structure of agriculture in central and eastern European countries, Electronic Journal of Agricultural and Development Economics Food and Agriculture Organization, 3, 225-275, 2006 a.

Thomas, J.: What's on regarding land consolidation in Europe?, in: Proceedings of the XXIII International FIG Congress, Munich, Germany, 8-13, 8-13 Ocotber, 2006b.

Tibshirani, R.: Regression shrinkage and selection via the lasso, J. Roy. Stat. Soc. B, 58, 267-288, 1996.

Tilahun, M., Vranken, L., Muys, B., Deckers, J., Gebregziabher, K., Gebrehiwot, K., and Mathijs, E.: Rural Households' demand for Frankincense Forest Conservation in Tigray, Ethiopia: A Contingent Valuation Analysis, Land Degrad. Dev., doi:10.1002/ldr.2207, online first, 2013.

Tsoukalas, L. H. and Uhrig, R. E.: Fuzzy and Neural Approaches in Engineering, John Wiley \& Sons, Inc., New York, USA, 1993.

TUIK: Tarm Saym Sonuclar, available at: tuik.gov.tr (last access: September 2014), 2001 (in Turkish). 
Wang, T., Yan, C. Z., Song, X., and Li, S.: Landsat images reveal trends in the aeolian desertification in a source area for sand and dust storms in china's alashan plateau (1975-2007), Land Degrad. Dev., 24, 22-429, 2013.

Wang, T.-C. and Lee H.-D.: Constructing a Fuzzy Decision Tree by Integrating Fuzzy Sets and Entropy, WSEAS Trans. Info. Sci. Appl., 8, 1547-1552, 2006.

Wang, W., Wang, Z. Y., and Klir, G. J.: Genetic algorithm for determining fuzzy measures from data, J. Intell. Fuzzy Syst., 6, 171$183,1998$.

Wang, Z.: A new genetic algorithm for nonlinear multiregressions based on generalized Choquet integrals, in: Proc. 12th IEEE Intern. Conference on Fuzzy Systems, St. Louis, Missouri, USA, 25-28 May 2003, 2, 819-821, 2003.

Yan, X. and Cai, Y. L.: Multi-Scale Anthropogenic Driving Forces of Karst Rocky Desertification in Southwest China, Land Degrad. Dev., 26, 193-200, 2015.

Yu, B., Stott, P., Di, X. Y., and Yu, H. X.: Assessment of land cover changes and their effect on soil organic carbon and soil total nitrogen in daqing prefecture, China, Land Degrad. Dev., 25, 520531, 2014.
Zadeh, L.: Fuzzy sets, Inform. Control, 8, 338-353, 1965.

Zhang, K., Zheng, H., Chen, F. L., Ouyang, Z. Y., Wang, Y., Wu, Y. F., Lan, J., Fu, M., and Xiang, X. W.: Changes in soil quality after converting Pinus to Eucalyptus plantations in southern China, Solid Earth, 6, 115-123, doi:10.5194/se-6-115-2015, 2015.

Zhao, G., Mu, X., Wen, Z., Wang, F., and Gao, P.: Soil erosion, conservation, and eco-environment changes in the loess plateau of china, Land Degrad. Dev., 24, 499-510, 2013.

Zhao, X., Wu, P., Gao, X., and Persaud, N.: Soil Quality Indicators in Relation to Land Use and Topography in a Small Catchment on the Loess Plateau of China, Land Degrad. Dev., 26, 54-61, 2015.

Zimmermann, H. J.: Fuzzy Set Theory and Its Applications, Kluwer Academic Publishers, Boston, USA, 1991. 